\title{
Avaliação na Perspectiva Acional e integração das atividades de linguagem em língua estrangeira
}

\author{
Luzia Alessandra Pinheiro \\ Secretaria de Estado de Educação do Distrito Federal \\ alessandra.pinheiro@edu.se.df.gov.br \\ Gladys Quevedo-Camargo \\ Universidade de Brasília \\ gladys@unb.br
}

\section{Resumo}

Este artigo aborda a avaliação em língua estrangeira na Perspectiva Acional, que tem como pressuposto unir a aprendizagem da língua ao seu uso social real por meio de tarefas nas quais há integração de habilidades. Tem por base uma pesquisa teórica realizada no âmbito de mestrado e versa sobre um processo avaliativo em língua estrangeira que visa associar as atividades de linguagem para aproximar a língua de seu uso real. O texto aborda aspectos sobre a Perspectiva Acional, os gêneros de textos, a avaliação para a aprendizagem e a integração das atividades de linguagem, particularmente de recepção e produção, na avaliação em sala de aula. Propõe que uma avaliação representativa do uso da língua em situações reais de comunicação recorra a procedimentos que integram as atividades de linguagem, como ocorre no mundo real. Os gêneros de textos orais e escritos configuram-se como insumos para agregar as atividades de linguagem. Vincular a recepção à produção de textos significa conferir mais autenticidade ao processo avaliativo na lógica acional. $\mathrm{O}$ intuito é proporcionar mais uma possibilidade pedagógica para o agir avaliativo do professor de línguas.

Palavras-chave: Perspectiva Acional. Avaliação para a aprendizagem. Gêneros de textos. Atividades de linguagem.

\section{Abstract}

This article focuses on foreign language assessment from the action-oriented approach perspective, which includes, among its premises, merging language learning and the real social use of the language by means of tasks in which skills are integrated. It reflects upon the issue of assessment practices that usually divide the language skills into listening, speaking, reading and writing. It makes 
considerations about the assessment process through the integration of language activities, particularly the receptive and productive ones, so as to favour pedagogical actions that mirror the real use of the language in classroom assessments. By means of a literature review, this text discusses the action-oriented approach, textual genres, assessment for learning as well as the integration of language activities in classroom assessments. It advocates for assessment practices that are representative of language use in real communicative situations and that rely on procedures that integrate language activities such as those taking place in real life. Oral and written textual genres consist in material to operationalize language activities. From the action-oriented approach perspective, connecting reception to text production means making the assessment process authentic. Our intention is to provide a pedagogical possibility to language teachers' assessment practices.

Keywords: Action-oriented approach. Assessment for learning. Textual genres. Language activities.

\section{Introdução}

Tradicionalmente, o ensino, a aprendizagem e a avaliação em língua estrangeira (doravante LE), visto que são dimensões indissociáveis (SCARAMUCCI, 2006), costumam ter como seu objeto as quatro habilidades: ouvir, falar, ler e escrever, separadamente. Na Perspectiva Acional (doravante PA), essas habilidades são (re)nomeadas de atividades de linguagem, dentre as quais destacamos a recepção (compreensão oral e escrita) e a produção (produção oral em interação/continuidade e escrita) (CONSEIL DE L'EUROPE, 2005).

Com base nessa visão, há uma probabilidade de modificar o objetivo didático de aprender uma LE, uma vez que corremos o risco de nos limitar à dimensão linguística, negligenciando os aspectos sociolinguísticos e pragmáticos (ROSEN, 2005), bem como de nos distanciarmos do uso da língua em situações reais de comunicação. 
De modo global, Porcher (2004) nos lembra que há uma única competência ${ }^{1}$ direcionada pela didática de LE: a capacidade de comunicar, o que nos remete à articulação do discurso, sua coesão, sua coerência, à identificação de gêneros de textos e aos contextos de uso (CONSEIL DE L'EUROPE, 2005). Em outras palavras, é preciso constatar que o usuário da língua se encontra em situação do seu uso simultâneo na recepção e na produção de textos.

Dessa maneira, é necessário propor-se a um entendimento acional da competência linguístico-comunicativa, cuja visão deve permitir observar a multidimensionalidade das atividades de linguagem que se alternam a um ritmo, às vezes, dificilmente identificável, em que recepção/produção se completam e reverberam, pressupostos inerentes à PA (RIBA, 2009).

Temos por escopo, neste artigo, a caracterização do processo avaliativo à luz da PA com foco na integração das atividades de linguagem (ou habilidades) em LE, haja vista que recepção e produção são interligadamente utilizadas em contexto real de comunicação. Escolhemos esta temática devido ao nosso propósito de oferecer ao professor de LE uma opção entre tantas cabíveis quando o assunto é avaliação para que possa proporcionar aos aprendentes um processo avaliativo mais próximo do uso real da língua capaz de ressaltar sua função social.

Do ponto de vista metodológico, é conveniente esclarecer que este artigo é um recorte de uma pesquisa de mestrado desenvolvida pela primeira autora deste artigo, de natureza teórica e exploratória, oriunda de um estudo de fundamentação bibliográfica. $O$ processamento das informações foi norteado pela abordagem qualitativa/interpretativa tendo por guia os objetivos da pesquisa, que foram: identificar fundamentos conceituais que poderiam subsidiar um processo avaliativo pedagógico em francês língua estrangeira (FLE) a partir da PA e delinear parâmetros para um processo avaliativo pedagógico em FLE em consonância com a PA (PINHEIRO, 2018).

Para explicar o tema proposto pelo artigo faremos uma breve conceituação da PA e de seus pressupostos, trataremos sobre o papel dos

\footnotetext{
${ }^{1}$ Entende-se competência como "o conjunto dos conhecimentos, capacidades e características que permitem a realização de ações" [Les compétences sont l'ensemble des connaissances, des habiletés et des dispositions qui permettent d'agir.] (CONSEIL DE L'EUROPE, 2005, p. 15).
} 
gêneros de textos na PA e sobre a avaliação para a aprendizagem como função avaliativa pedagógica e discorreremos a respeito da integração das atividades de linguagem.

\section{Conceituação da Perspectiva Acional e de seus pressupostos}

Esta seção baseia-se fortemente no Quadro Europeu Comum de Referências para Línguas (CONSEIL DE L'EUROPE, 2005) (doravante Quadro) pelo fato de ele ter sido o primeiro documento a estruturar e propor o conceito da PA, tornando-se, assim, referencial essencial para a conceituação e a compreensão dessa perspectiva. No entanto, recorremos também a outros autores, mas que por sua vez também fazem referência ao Quadro.

A PA advém do contexto europeu da didática de línguas, tendo em conta que constitui a pedra filosofal do Quadro, a chave que permite transformar a abordagem comunicativa (doravante AC) em uma matéria mais nobre e rica de esperança pedagógica: esta da ação, sendo o elemento principal dessa perspectiva (SPRINGER, 2009).

Nesse sentido, a PA configura-se de certa maneira como um prolongamento da AC, a qual fora assim nomeada por ser seu objetivo social de referência a formação do aprendente para comunicar-se em LE (BÉRARD, 2009; PUREN, 2009; TAGLIANTE, 2005). Esses autores asseveram que a apelação de "perspectiva acional" para o Quadro é também devidamente lógica, pois o objetivo fixado é a formação de um ator social, ou seja, o "falar com" inerente à AC movimenta-se para o "agir com" na PA, sem prescindir do primeiro.

Para que isso ocorra precisamos perceber que o componente linguístico não basta, sendo necessária sua mobilização com as dimensões sociolinguísticas e pragmáticas. Nesse sentido, essa perspectiva para ensinar, aprender e avaliar LE fundamenta-se sobre as noções do aprendente como ator social em uma visão de resolução de problemas (tarefas) por envolver a mobilização simultânea de competências, fato que deve ser espelhado no processo avaliativo.

Dessa forma, o Quadro apresenta uma concepção teórica sobre a PA intrínseca à noção de uso e aprendizagem de uma língua, ou seja, aprender uma língua equivale a ser capaz de usá-la, realçando o caráter 
social da linguagem. Segundo Perrichon (2009, p. 91), a "Perspectiva Acional corresponde ao elo entre esses dois tipos de ação [aprender e usar a língua]. Entretanto, embora definido recentemente pelo Quadro, trata-se, na verdade, de uma redescoberta":

$\mathrm{O}$ uso de uma língua abrangendo a sua aprendizagem inclui as ações realizadas pelas pessoas que, como indivíduos e como atores sociais, desenvolvem um conjunto de competências gerais e, particularmente, competências linguístico-comunicativas. ${ }^{2}$ As pessoas utilizam as competências à sua disposição em vários contextos, em diferentes condições, sujeitas a diversas limitações, com o fim de realizarem atividades de linguagem que implicam processos linguísticos para produzirem e/ou receberem textos relacionados com temas pertencentes a domínios específicos. Para tal, ativam as estratégias que lhes parecem mais apropriadas para o desempenho das tarefas a realizar. O controle dessas ações pelos interlocutores conduz ao reforço ou à modificação das suas competências (CONSEIL DE L'EUROPE, 2005, p. 15, grifos dos autores). ${ }^{3}$

Sumariamente, a PA evidencia como particularidades os seguintes elementos necessários à sua compreensão: competências gerais-individuais, competência linguístico-comunicativa, atividades de linguagem, domínios, tarefas, estratégias e textos.

Podemos compreender que há um novo aporte trazido pela PA no que concerne às abordagens de ensino precedentes, como por exemplo a consideração do conjunto de conhecimentos anteriores do aprendente. A esse conjunto de competências pessoais o Quadro atribui o nome de competências gerais-individuais, quais sejam: saber, saber-fazer, saber-ser e saber-aprender, que moldam a capacidade de aprendizagem da competência linguístico-comunicativa em LE.

Logo, "as competências gerais-individuais não são as específicas da língua, mas aquilo a que se recorre para realizar atividades de todo tipo, incluindo as atividades linguísticas" (CONSEIL DE L'EUROPE, 2005, p.

\footnotetext{
${ }^{2}$ Competência linguístico-comunicativa é o termo usado para a tradução nossa de compétence à communiquer langagièrement, da versão francesa do Quadro (CONSEIL DE L'EUROPE, 2005).

${ }^{3}$ Todas as traduções são de nossa responsabilidade, exceto quando sinalizado outro tradutor.
} 
15). São, portanto, adquiridas no curso de experiências passadas dos aprendentes da língua e evoluem de acordo com as vivências do presente e a advir. São distintas da competência linguístico-comunicativa, mesmo que contribuam estreitamente para essa.

Com relação à competência linguístico-comunicativa, o Quadro propôs um modelo dito "acional", pouco distante da abordagem "comunicativa", mas centrado sobre as ações que o aprendente pode realizar na língua que deseja aprender (TAGLIANTE, 2005). Esse modelo é composto pelos componentes linguístico, sociolinguístico e pragmático, sendo que o primeiro componente, de acordo com o Quadro (CONSEIL DE L'EUROPE, 2005), se declina em competência lexical, gramatical, semântica, fonológica, ortográfica e ortoépica. O segundo versa sobre os marcadores de relações sociais, regras de polidez, expressões da sabedoria popular, diferenças de registros (oficial, formal, neutro, informal, familiar, íntimo), dialetos e sotaques. E, por fim, o terceiro diz respeito ao conhecimento que os aprendentes têm da organização e da estruturação de mensagens e discursos, ou seja, dos gêneros de textos.

Assim, esses componentes das competências na PA são mobilizados pelos aprendentes em diferentes domínios (esferas de ação ou áreas de interesse) e condições ao realizarem as atividades de linguagem que podem estar relacionadas à recepção, à produção, à interação e à mediação.

As atividades de linguagem abrangem o "exercício da própria competência linguístico-comunicativa em língua em um determinado domínio específico no processamento (recepção e/ou produção) de um ou mais textos, com vistas à realização de uma tarefa" (CONSEIL DE L'EUROPE, 2005, p. 15). A noção adotada por nós de tarefa equivale à definição do Quadro (CONSEIL DE L'EUROPE, 2005), segundo o qual tarefas são atividades que as pessoas fazem nos diferentes domínios pessoal, público, educacional e profissional.

De acordo com o Quadro (CONSEIL DE L'EUROPE, 2005), as atividades de recepção remetem-nos às atividades de compreensão oral (escuta) e escrita (leitura), enquanto as atividades de produção se referem à produção oral (discurso oral) e à escrita (discurso escrito). As atividades de interação abarcam a interação oral e escrita, o que nos faz concluir que a produção oral ou escrita se subdivide em continuidade (produção monológica) e interação (produção dialógica). 
Além de apelar para as estratégias cognitivas, a interação faz recurso às estratégias de cooperação que contribuem para o bom funcionamento da colaboração entre os interlocutores, sobretudo no que tange à gestão dos turnos de fala e compreensão da mensagem. Rosen (2005) destaca que a interação, conforme proposta pelo Quadro (CONSEIL DE L'EUROPE, 2005), não se apresenta como uma atividade de linguagem inovadora, haja vista que também constitui o cerne da AC.

Quanto à mediação, ela é entendida como reformulação, tradução, interpretação, resumos orais ou escritos para um terceiro participante na comunicação (CONSEIL DE L'EUROPE, 2005). North e Piccardo (2016) relatam que a mediação é a integradora da co-construção do sentido na comunicação, indo além dessa função ao sublinhar o fluxo constante entre as dimensões individuais e sociais do uso da língua.

Isso posto, para o corpo deste artigo fazemos a opção tão somente por empregar a recepção e a produção, que "na realidade se entrelaçam em toda situação de comunicação escolar ou fora dela e que conduzem, por exemplo, as atividades de interação e de mediação de uma certa forma" (CUQ; GRUCA, 2017, p. 145).

Para a realização dessas atividades de linguagem, o aprendente aciona as estratégias. Segundo o Quadro, estratégias são "um meio que o usuário da língua explora para mobilizar e equilibrar os seus recursos, para colocar em prática capacidades e procedimentos, de modo a responder às exigências da comunicação" (CONSEIL DE L'EUROPE, 2005, p. 48). Tais estratégias são empregadas no cumprimento de tarefas linguísticas que requerem a escolha de um texto, "uma sequência discursiva oral ou escrita" (CONSEIL DE L'EUROPE, 2005). Por conseguinte, "não haveria ato de linguagem sem texto" (CUQ; GRUCA, 2017, p. 160).

Aos gêneros de textos atribuímos um lugar de destaque para a abordagem sob a lógica acional, tendo em conta que a PA sugere uma filiação às teorias ditas construtivistas e socioconstrutivistas adequadas aos modelos didáticos, considerando a ação do aprendente como primeiro princípio explicativo do processo de aprendizagem (PUREN, 2009; SPRINGER, 2009; BENTO, 2013). Todavia, o Quadro (CONSEIL DE L'EUROPE, 2005) não se fundamenta [ou anuncia não se fundamentar] em nenhuma teoria de aprendizagem para a concepção da PA (CONSEIL DE L'EUROPE, 2005, PUREN, 2009). 
Na sequência, expomos alguns aspectos dos gêneros de textos, cuja compreensão é de suma relevância para a caracterização do processo avaliativo sob a lógica acional com foco na integração das atividades de linguagem.

\section{Gêneros de textos e o agir social}

Bronckart (2009), principal expoente do Interacionismo Sociodiscursivo (ISD), descreve que as atividades de linguagem ocorrem no âmbito de formações sociodiscursivas com a participação de agentes singulares como polo de ações de linguagem. Assevera que os textos são formas comunicativas globais e finitas, constituindo os produtos concretos das ações de linguagem, que se distribuem em gêneros, os quais estão disponíveis no intertexto, compreendido como construto sócio-histórico. Por fim, os tipos de discurso conectam-se a determinadas formas linguísticas.

O conhecimento dos gêneros de textos é definido como um "mecanismo fundamental de socialização, de inserção prática nas atividades comunicativas humanas" (BRONCKART, 2009, p. 100). "A linguagem é, portanto, primariamente uma característica da atividade social humana, cuja função maior é de ordem comunicativa ou pragmática" (BRONCKART, 2009, p. 34).

De tal modo, descrever um agir ou ação de linguagem ${ }^{4}$ consiste em uma tomada de decisão do agente produtor "em escolher, dentre os gêneros de textos disponíveis na intertextualidade, ${ }^{5}$ aquele que lhe parece o mais adaptado e o mais eficaz em relação à sua situação de ação" (BRONCKART, 2009, p. 100), ou seja, optar por modelos de organização

\footnotetext{
4"Uma ação de linguagem consiste em produzir, compreender e interpretar elou memorizar um conjunto organizado de enunciados orais ou escritos (um texto, no sentido geral [...])" (SCHNEUWLY; DOLZ, 1997, p. 28, grifos dos autores).

5"O intertexto é constituído pelo conjunto de gêneros textuais elaborados pelas gerações precedentes, tais como utilizados e eventualmente transformados e reorientados pelas formações sociais contemporâneas" (BRONCKART, 2009, p. 100 , grifo do autor).
} 
textual. Aos modelos de organização textual, Bronckart (2009) denomina de gêneros de textos.

Na perspectiva do ISD, a noção de texto designa

[...] toda unidade de produção verbal que veicula uma mensagem linguisticamente organizada e que tende a produzir um efeito de coerência em seus destinatários [...]. Ao fazer isso, adotamos ao mesmo tempo a acepção corrente do termo (segundo a qual esse termo designa todo exemplar de produção escrita [...] e a acepção mais abrangente [...] (segundo a qual esse termo também designa as unidades comunicativas originalmente produzidas em modalidade oral [...]. (BRONCKART, 2009, p. 137).

Compreendemos que essa visão vai ao encontro da concepção de atividades de linguagem na PA, cuja abordagem sociointeracionista [e acional] de aprendizagem da língua

[...] leva em conta as práticas de linguagem como uma das práticas de interação social (situação enunciativa e ambiente discursivo), implicando, além de dimensões sociais, as cognitivas e linguísticas do funcionamento da linguagem numa determinada situação comunicativa (PAVIANE, 2011, p. 70).

Marcuschi (2008) afirma que, ao desejar produzir alguma ação linguística em situação real, se recorre a algum gênero textual. ${ }^{6}$ É a existência dos gêneros de textos que viabiliza a comunicação. Faraco (2009, p. 131) acrescenta que "aprender os modos sociais de fazer é também aprender os modos sociais de dizer" e vice-versa.

Dentre os possíveis elementos para uma abordagem didática dos gêneros de textos, consideramos dois para este artigo: a caracterização de seus traços linguísticos e discursivos identificados por meio de sua arquitetura textual (BRONCKART, 2009) e as capacidades de linguagem (DOLZ; SCHNEUWLY, 2004; CRISTOVÃO; STUTZ, 2011). A respeito da arquitetura textual, de acordo com Bronckart (2009), a organização de

${ }^{6}$ Para exemplos de gêneros textuais: Marcuschi (2008, p. 194-197). 
um texto consta de três camadas justapostas: a infraestrutura geral do texto, os mecanismos de textualização e os mecanismos enunciativos.

Diretamente ligadas aos níveis da arquitetura textual estão as capacidades de linguagem (LOUSADA, 2009). "A noção de capacidades de linguagem [...] evoca as aptidões requeridas do aprendiz para a produção de um gênero numa situação de interação determinada [...]" (DOLZ; SCHNEUWLY, 2004, p. 52). De acordo com os respectivos autores, as capacidades de linguagem classificam-se em três: de ação, discursiva e linguístico-discursiva. Todavia, Cristovão e Stutz (2011) propõem uma abrangência dessas capacidades ao incluírem a capacidade de significação.

Cristovão (2007, p. 35) ratifica a importância de que o professor "entenda seu funcionamento [dos gêneros de textos] e as capacidades de linguagem que constituem seus textos, e que estes não sirvam apenas como modelos ou pretextos para o ensino de vocabulário ou da gramática". Embasar o ensino de uma língua em gêneros de textos deixa transparecer que os segmentos linguísticos ocupam um lugar necessário, haja vista que fazem parte da modalidade textual, porém secundário, havendo um espaço para as dimensões sociolinguística e pragmática. A linguagem é vista "sobretudo como forma de ação e, neste caso, deve ser analisada como atividade e não como estrutura" (MARCUSCHI, 2008, p. 22).

Em suma, “o ideal acional com o 'seu viver com' e 'agir juntos' [e sua visão de aprendente como ator social] passa a influenciar o campo da avaliação" (SPRINGER, 2009, p. 33), o que exige um avanço nas práticas avaliativas. Esclarecemos que a avaliação de que tratamos corresponde ao contexto pedagógico diferentemente do contexto certificativo. Por isso a função avaliativa por nós privilegiada é a avaliação orientada para a aprendizagem (CARLESS, 2006), doravante avaliação para a aprendizagem.

\section{A avaliação para a aprendizagem}

Segundo Carless (2006), o objetivo da avaliação para a aprendizagem é fortalecer a aprendizagem, ao que crê poder ser alcançado por meio de diferentes procedimentos, desde que o foco seja a engenharia da instrução apropriada ao aprendente, dentre os quais destacamos, sem pormenores, o feedback (ALLAL; MOTTIER LOPEZ, 2005; CARLESS, 
2006; CONSEIL DE L'EUROPE, 2005) e a autoavaliação (CONSEIL DE L'EUROPE, 2005, GAUTHEROT, 2009; HUVER; SPRINGER, 2011).

Cientes de que o termo avaliação se refere a uma "gama de métodos e abordagens para coletar informações de modo a tomar decisões sobre o aprendizado em contraste ao termo teste, usado para se referir a uma forma de avaliação" (KATZ, 2012), optamos pela seguinte definição, em que avaliar

[...] consiste em reunir um conjunto de informações (pertinentes, válidas e confiáveis) para examinar o grau de adequação entre elas e um conjunto de critérios (pertinentes, válidos e confiáveis) que representem, adequadamente, o tipo de resultados esperados $e$ lhes dê sentido em vista de fundamentar uma tomada de decisão (DE KETELE, 2013, p. 3).

Dentre os tipos, não exaustivos, de avaliação apresentados pelo Quadro (CONSEIL DE L'EUROPE, 2005, p. 139), consideramos para uma avaliação sob a lógica acional a avaliação de desempenho, a qual solicita ao aprendente que produza uma amostra do discurso oral ou escrito. "Nesse caso, significa um desempenho [do aprendente] relevante numa situação (relativamente) autêntica e frequentemente relacionada com o estudo" (CONSEIL DE L'EUROPE, 2005, p. 142). Todavia, não está excluída a avaliação do conhecimento, pois segundo o Quadro "é possível equilibrar a avaliação do desempenho com uma avaliação de conhecimentos da língua como sistema" (CONSEIL DE L'EUROPE, 2005, p. 142).

Isso equivale a dizer que a PA privilegia a abordagem avaliativa por competência e questiona a avaliação estruturalista da língua, cujo foco maior está na forma (HUVER; SPRINGER, 2011). Em outras palavras, aquilo que o aprendente é capaz de fazer com a língua e, não ou tão somente, o que ele sabe sobre a língua; uma abordagem avaliativa que estabelece um elo entre o pedagógico e a ação social. A compreensão acional de competência, além de fundamentar-se no uso autêntico da língua, alicerça-se na noção de aprendente ator social e de tarefa. Em termos de avaliação, equivale a questionar se a tarefa [atividade avaliativa] é representativa de uma atividade social que o aprendente teria realmente de fazer na língua que aprende (TAGLIANTE, 2005). 
Assim, vislumbrar o ensino, a aprendizagem e a avaliação de LE por meio das atividades de linguagem separadamente não condiz com as situações de uso real da língua, além de ser um obstáculo para contemplar os componentes sociolinguísticos e pragmáticos. Em outras palavras, questionamos como as avaliações das atividades de linguagem de maneira desmembradas (ouvir, falar, ler, escrever), não raramente por meio de itens fechados que permitem uma única possibilidade de resposta, podem, além do aspecto linguístico, fornecer inferências sobre o desempenho, uma vez que, geralmente, não solicitam amostras do discurso.

Segundo Bourguignon (2003, 1. 1315-1317-1318), uma abordagem avaliativa sob os princípios da PA, por conseguinte, de uma compreensão acional da competência linguístico-comunicativa

\begin{abstract}
[...] não repousa sobre 'exercícios típicos adaptados a cada estágio de aprendizagem'. O alicerce da avaliação será um cenário, ou seja, 'uma simulação [com ancoragem na vida real] constituída de um encadeamento de uma série de tarefas comunicativas efetuadas com vistas a alcançar o cumprimento de uma missão complexa de acordo com um determinado objetivo.
\end{abstract}

Para levar em conta a visão social, e consequentemente o agir social complexo pela competência, parece difícil manter a ideia de uma avaliação clássica dos fundamentos escolares (gramática e léxico), tampouco continuar avaliando as atividades de linguagem em separado, sendo necessário repensar as situações de aprendizagem e de avaliação a fim de que possam oferecer, efetivamente, a possibilidade de construir um verdadeiro agir complexo (HUVER; SPRINGER, 2011). O ato de comunicação merece um tratamento outro que não seja uma abordagem sistematicamente fragmentada em instrumentos desconectados uns dos outros (BOURGUIGNON, 2003), tampouco que se configure em uma amostra compartimentada da língua.

$\mathrm{O}$ ato de avaliar na PA supõe recursos a procedimentos que sejam realistas e acionais. Realistas, pois não devem avaliar o conhecimento e/ou a competência pela competência, mas para desenvolver uma competência linguístico-comunicativa com vistas à utilização da língua em situações reais de uso (CONSEIL DE L'EUROPE, 2005). Acionais, porque não se trata apenas do conhecimento linguístico, mas da sua expressão na 
competência linguístico-comunicativa na ação (CONSEIL DE L'EUROPE, 2005; TAGLIANTE, 2005; PUREN, 2009; HUVER; SPRINGER, 2011) manifesta e contextualizada no quadro das atividades sociais de linguagem (BRONCKART, 2009) de ordem linguística e extralinguística (CONSEIL DE L'EUROPE, 2005).

\section{Atividades de linguagem integradas}

Compreendemos que a PA direciona o processo avaliativo para as atividades de linguagem de recepção e produção, pois são elas que abrangem o exercício da própria competência linguístico-comunicativa em língua (CONSEIL DE L'EUROPE, 2005). Recepção, produção, interação e mediação são categorias especificadas pelo Quadro para cada uma das atividades de comunicação da linguagem,

Essas categorias permitem a sua integração nas atividades comunicativas ou organização de uma metodologia de ensino por atividades de linguagem (CUQ; GRUCA, 2017), como costuma ocorrer tradicionalmente. Entretanto, no quadro acional, integrar recepção e produção (BOURGUIGNON, 2003; HUVER; SPRINGER, 2011) constitui uma prerrogativa, pois é essa integração que confere autenticidade para o ato de comunicação, uma vez que alguém fala ou escreve para transmitir uma mensagem a outrem com a finalidade de provocar uma ação.

Esse posicionamento alicerça-se na premissa de que somente há produção se houver compreensão (BOURGUIGNON; DELAHAYE; VICHER, 2005), ressaltando a interdependência entre recepção e produção. As atividades avaliativas devem ser ligadas a um objetivo comunicativo, isto é, não se escuta ou lê para identificar tópicos de gramática ou de vocabulário, mas para se comunicar por meio de um texto, recapitulando, uma sequência discursiva oral ou escrita.

Por sua vez, são as atividades de linguagem de produção que configuram o uso da língua em suas dimensões linguística, sociolinguística e pragmática. Conferem liberdade, criatividade, dinamicidade, personalidade e naturalidade ao aprendente no uso da língua, uma vez que compõem um quadro no qual a linguagem é utilizada como discurso para comunicação. Em outras palavras, as atividades de linguagem de produção permitem a ação de linguagem que deve resultar em um texto vinculado à 
recepção. Porém, na avaliação, não se recomenda que sejam produzidos $e x$ nihilo, mas com base em um documento de recepção e, assim, recursivamente, isto é, tendo um gênero de texto como insumo.

$\mathrm{Na} \mathrm{PA}$, a aprendizagem e o uso da língua envolvem ações de linguagens dos aprendentes para produzirem ou receberem textos (enunciados) ao realizarem uma atividade de linguagem de acordo com um tema e domínio na realização de uma tarefa (CONSEIL DE L'EUROPE, 2005). Se se espera dos aprendentes que sejam capazes de compreender ou de produzir textos ancorados em situações reais de uso, não faz sentido avaliar por meio de exercícios que não propiciam a construção de novos textos, tampouco por meio do desmembramento das atividades de linguagem em quatro ou em momentos estanques para cada uma delas.

Sendo a competência o foco da avaliação da língua, como na PA, o processo avaliativo deve ser baseado no desempenho, ou seja, em um comportamento observável da competência linguístico-comunicativa em ação (TAGLIANTE, 2005; HUVER; SPRINGER, 2011), abrindo-se a uma correção interpretativa.

Outrossim, atividades avaliativas elaboradas com base em uma correção objetiva são um pouco redutoras em relação às situações de uso real da língua, mesmo sendo importantes para a aprendizagem (BOURGUIGNON, 2003), além de geralmente excluírem os componentes sociolinguísticos e pragmáticos. Não significa, portanto, negligenciar os aspectos linguísticos, tais como a gramática ou o léxico. Significa que, na PA, esses elementos não constituem mais os objetivos linguísticos, mas na verdade são ferramentas linguísticas acionadas na construção de um texto, isto é, são elementos do saber em função do saber-fazer, de um objetivo maior, que é o agir de linguagem. 


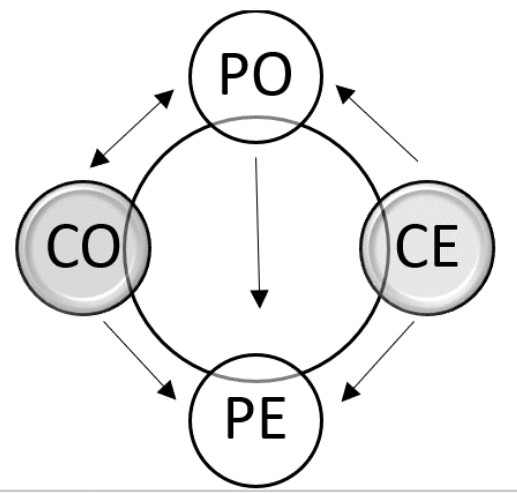

Figura 1. Atividades de linguagem integrada

Fonte: elaboração das autoras

Desse raciocínio resulta que um modelo de avaliação acional privilegia a produção oral (PO) e a produção escrita (PE) como produto das atividades avaliativas interligadas à compreensão oral $(\mathrm{CO})$ e à compreensão escrita $(\mathrm{CE})$. A recepção deve estar vinculada à produção, conforme o arranjo de possibilidades da seguinte figura que propomos:

Com essa figura queremos transmitir a ideia de que um texto de $\mathrm{CO}$ pode ser insumo para uma PO. Da mesma forma, uma CE pode fornecer input tanto para uma $\mathrm{PO}$ e/ou PE, criando, desse modo, novos discursos, tais quais ocorrem em uma situação real de comunicação. Assim, apresentamos a seguinte concepção: avaliar na PA implica a associação entre as atividades de linguagem de recepção e produção, de sorte que o aprendente receba um texto e que o resultado seja, também, um texto nas atividades avaliativas.

A compreensão de um texto (recepção) é essencial para a produção do segundo na atividade avaliativa. Em outras palavras, uma atividade de linguagem constitui subsídio para a realização de outra atividade de linguagem. Mais claramente: se a atividade avaliativa é de PE, pode ser vinculada à leitura $(\mathrm{CE})$, ou, com base em uma $\mathrm{CO}$ pode-se propor uma $\mathrm{PO}$ e/ou proceder-se a uma PE. As possibilidades de integração variam de acordo com a criatividade do professor, com o programa de ensino e com o estágio de aprendizagem dos aprendentes. 
Considerando que os gêneros de textos representam o quadro das atividades de linguagem, seu uso didático pode auxiliar os aprendentes a desenvolverem a competência linguístico-comunicativa, a compreenderem e produzi-los para agirem de maneira autônoma e desenvolta. Ademais, facilitam a entrada de documentos autênticos ou adaptados na sala de aula e enfatizam o caráter pragmático e discursivo da linguagem, aproximando as atividades avaliativas de situações de uso real da língua. É importante que a escolha dos gêneros de textos priorize diversos domínios e fontes variadas bem como a diversidade social, cultural e linguística onde determinada língua é falada.

As atividades avaliativas que buscam integrar as atividades de linguagem são elaboradas mediante um enunciado, ou seja, aquilo que é solicitado ao aprendente para fazer. Isso significa que não condiz com a lógica acional uma avaliação feita, por exemplo, por meio de itens de múltipla escolha. Melhor dizendo, se o insumo é um texto, o produto deve ser também um texto, por isso se faz necessário o emprego de critérios para a interpretação dos resultados.

Uma ficha de avaliação com descritores de critérios mostra-se fortemente útil e necessária, nesse caso, para atenuar a subjetividade (TAGLIANTE, 2005). De acordo com Huver e Springer (2011, p. 106), "um referencial de avaliação contém, no mínimo, dois tipos de informações: os critérios e os descritores, cuja mobilização conjunta permite guiar a interpretação do avaliador", ou do professor.

Critério é definido como característica ou propriedade segundo a qual se emite um juízo de valor ou uma apreciação sobre um desempenho (produção observável) e pode ser usado na avaliação para a aprendizagem, na qual são elementos indispensáveis na comunicação pedagógica (TAGLIANTE, 2005; HUVER; SPRINGER, 2011). Os critérios devem ser precisos e comunicados ao aprendente a fim de que ele conheça as condições da avaliação. No caso da PA, devem fazer mostra de um amálgama de saberes linguísticos (uso de estruturas, da morfossintaxe e do léxico) e do saber-fazer de particularidade comunicativa (realização de uma ação de linguagem) (TAGLIANTE, 2005), sociolinguística e pragmática. Entendemos que os critérios devem ser elaborados com uma linguagem não técnica, de modo que se considere seu destinatário - o aprendente.

Os descritores ou indicadores referem-se a um elemento significativo, notável em um conjunto de dados, e permitem avaliar uma 
situação, um processo, um produto, em princípio sempre referente a um critério (TAGLIANTE, 2005). A utilização de descritores

[...] tornou-se cada vez mais frequente nestes últimos dez anos, cuja experiência tem mostrado que a coerência usada pelos professores e pelos aprendentes para interpretarem os descritores é reforçada se os descritores descreverem não só $O$ QUE os aprendentes são capazes de fazer, mas também COMO (e a que estágio de qualidade) devem fazê-lo (CONSEIL DE L'EUROPE, 2005, p. 138, grifos dos autores).

Cientes de que este artigo que procura divulgar concepções sobre avaliação para a aprendizagem possa carecer de ilustrações sobre os procedimentos pedagógicos visados, esclarecemos que esses procedimentos se encontram exemplificados no texto de origem (PINHEIRO, 2018).

Enfim, integrar as atividades de linguagem no processo avaliativo de LE permite aos aprendentes expressarem sua criatividade e originalidade, conferindo-lhes autonomia e liberdade em suas escolhas discursivas. Tornam-se responsáveis por suas produções e escolhas estratégicas. A integração das habilidades também revela o caráter de imprevisibilidade, inerente ao ato real de comunicação.

Podemos afirmar que integrar as habilidades de linguagem configura um recurso para aproximar todo o processo de ensinoaprendizagem-avaliação às situações de uso real da LE. Tal processo representa a complexidade do ato de comunicação ao envolver tanto os elementos da competência linguístico-comunicativa e o meio pelo qual eles se manifestam, a recepção e a produção

de textos orais e escritos, assim como as competências gerais-individuais.

\section{Considerações finais}

Este artigo teve por finalidade abordar uma questão de relevância e interesse do campo pedagógico, principalmente no que concerne à avaliação da aprendizagem em LE. Por ser um recorte de um estudo 
teórico, limitou-se a refletir sobre a integração das atividades de linguagem no processo avaliativo em LE à luz da Perspectiva Acional.

Acreditamos que a avaliação para a aprendizagem em LE deve aproximar-se do uso real da língua e privilegiar a linguagem como instrumento de ação social. Para tanto, a integração das atividades de linguagem com o uso de gêneros de textos surge como uma prática pedagógica avaliativa prolífera para favorecer o desenvolvimento da competência linguístico-comunicativa na complexidade de seus componentes linguístico, sociolinguístico e pragmático.

Embora tal temática já tenha expansões e revisões extensivamente publicadas, trata-se de uma prática ainda pouco presente na sala de aula de LE, uma vez que a experiência docente nos mostra que os instrumentos de avaliação nesse contexto se têm proposto a avaliar separadamente o que chamam de "parte" oral (ouvir e falar) e "parte" escrita (ler e escrever).

Avaliar na Perspectiva Acional remete a privilegiar práticas avaliativas que visam à integração das atividades de linguagem, cujo objetivo maior é a compreensão e a produção de um texto, uma unidade discursiva. Integrar as atividades de linguagem demonstra que em LE não se deve pensar na avaliação como algo a ser posto em "partes", mas sim em um "todo". Um todo que considera o uso real que as pessoas fazem da língua no seu dia a dia: a compreensão e a produção de textos. Isso implica, de certa forma, a quebra de um forte paradigma.

\section{Referências}

ALLAL, Linda.; MOTTIER LOPEZ, Lucie. Formative assessment of learning: a review of publications in French. French Literature Review, University of Geneva, p. 241-262, 2005. Disponivel em: <http://www.oecd.org/education/ceri/35337948.pdf>. Acesso em: 8 abr. 2018.

BENTO, Margaret. Regards théoriques sur la perspective actionnelle. Revues.org, Rennes, p. 87-100, 2013. Disponível em: <https://journals.openedition.org/educationdidactique/1404 >. Acesso em: out. 2017. 
BÉRARD, Évelyne. Les tâches dans l'enseignement du FLE: rapport à la réalité et dimension didactique. Le français dans le monde, Paris, n. 45, Jan. 2009.

BOURGUIGNON, Claire. L'apprentissage des langues para l'action. In: LIONS-OLIVIERI, M.-L.; LIRIA, P. L'approche actionnelle dans l'enseignement des langues. 2e édition. ed. [S.1.]: Editions Maison des Langues. Edição do Kindle., 2003. Não paginado.

BOURGUIGNON, Claire.; DELAHAYE, Philippe.; VICHER, Anne. L'évaluation de la compétence en langue: un objectif commum pour des publics différents. Ela. Études de linguistique appliquée, p. 459-473, 2005. ISSN 140. Disponível em: <https://www.cairn.info/revue-ela-20054-page-459.htm>. Acesso em: 7 ago. 2018.

BRONCKART, Jean-Paul. Atividade de linguagem, textos e discursos. 2. ed. São Paulo: PUC-SP, 2009.

CARLESS, David. Differing perceptions in the feedback process. Studies in higher education, v. 31, n. 2, p. 219-233, April 2006.

CONSEIL DE L'EUROPE, Cadre européen commun de référence pour les langues. Paris: Didier, 2005.

CRISTOVÃO, Vera Lúcia Lopes. O Interacionismo Sociodiscursivo e o ensino de línguas com uma abordagem baseada em gêneros textuais. In: Modelos didáticos de gênero: uma abordagem para o ensino de língua estrangeira. Londrina: UEL, 2007. p. 9-28.

CRISTOVÃO, Vera Lúcia Lopes; STUTZ, Lidia. A construção de uma sequência didática na formação docente inicial de língua inglesa.

SIGNUM: Estud. Ling., Londrina, v. 14, n. 1, p. 569-589, jun. 2011.

CUQ, Jean-Pierre.; GRUCA, Isabelle. Cours de didactique du français langue étrangère et seconde. 4 . ed. Grenoble: Presses universitaires de Grenoble, 2017. 
DE KETELE, Jean-Marie. Evaluation et enseignement: pour quels objectifs? par quels moyens? Rev. franç. de linguistique appliquée, 2013, XVIII-1, Louvain, v. XVIII-1, p. 5-8, 2013. Disponível em:

$<$ https://www.cairn.info/revue-francaise-de-linguistique-appliquee-2013-1page-3.htm>. Acesso em: 4 abr. 2018.

DOLZ, Joaquim.; SCHNEUWLY, Bernard. Gêneros e progressão em expressão oral e escrita - elementos para reflexões sobre uma experiência suíça (francófona) gêneros orais e escritos na escola. In: Gêneros orais e escritos na escola. Campinas: Mercado das Letras, 2004. p. 41-70.

\section{FARACO, Carlos Alberto. Linguagem \& Diálogo: as ideias linguísticas} do círculo de Bakhtin. São Paulo: Parábola Editorial, 2009.

GAUTHEROT, Jean-Marie. Glossaire des termes du CECR. Le français dans le monde, Paris, n. 45, p. 169-191, Janvier 2009.

HUVER, Emmanuelle; SPRINGER, Claude. L'évaluation en langues nouveaux enjeux et perspectives. Paris: Didier, 2011.

KATZ, Anne. Linking assessment with instructional aims and learning. In: COOMBE, Christine; DAVIDSON, Peter; O' SULLIVAN, Barry; STOYNOFF, Stephen. (Eds.) The Cambridge guide to second language assessment. Cambridge: Cambridge Univerity Press, 2012. p. 66-73.

LEWIS, Marilyn. Feedback em aulas de idiomas. Tradução de Renata Lea F. Oliveira. São Paulo: Special Books Services Livraria - Porfolio SBS 7, 2003.

LOUSADA, Eliane Gouvêa. Gêneros textuais e ensino de produção escrita: um caso de ensino do francês em nível universitário. SIGNUM: Est. Ling., Londrina, v. 2, p. 167-184, dez. 2009.

MARCUSCHI, Luís Antônio. Produção textual, ánalise de gênero e compreensão. São Paulo: Parábola Editorial, 2008. 
NORTH, Brian; PICCARDO, Enrica. Elaborer des descripteurs illustrant des aspects de la médiation pour le Cadre. Strasbourg: Conseil de l'Europe, 2016. Disponivel em: <https://www.coe.int/en/web/portal/home>. Acesso em: mar. 2018.

PAVIANI, Neires Maria Soldatelli. Aprendizagem na perspectiva da teoria do interacionismo sociodiscursivo de Bronckart. Revista Espaço Pedagógico, Passo Fundo, v. 8, p. 58-73, jan./jun. 2011.

PERRICHON, Emilie. Perspective actionnelle et pédagogie du projet: de la culture individuelle à la construction d'une culture d'action collective. Synergies Pays Riverains de la Baltique, n. 6, p. 91-111, 2009.

PORCHER, Louis. L'enseignement des langues étrangères. Paris: Hachette, 2004.

PUREN, Christian. Conclusion-synthèse: variations sur la perspective de l'agir social en didactique des langues-cultures. In: Le Français dans le monde: La perspective actionnelle et l'approche par les tâches en classe de langues. Le français dans le monde, Paris, n. 45, p. 154-168, Janvier 2009.

RIBA, Patrick. Conception et validité de tâches évaluatives dans une perspective actiionnelle. Le français dans le monde, Paris, n. 45, p. 124133, jan. 2009.

ROSEN, Evelyne. La mort annoncée des "quatre compétences": pour une prise en compte du répertoire communicatif des apprenants en classe de FLE. Revue de Sociolinguistique em Ligne, n. 6, p. 120-133, 2005. Disponível em: <http://glottopol.univ-rouen.fr/numero_6.html>. Acesso em: 2 fev. 2020.

SCARAMUCCI, Mathilde Regina Virgínia. O professor avaliador: sobre a importância da avaliação na formação do professor de língua estrangeira. In: ROTTAVA, Luciana; SANTOS, Sulany Silveira dos. (Org.). Ensinoaprendizagem de línguas: língua estrangeira, Ijuí: Ed. Unijuí, 2006. p. 49-64. 
SPRINGER, Claude. La dimension sociale dans le CECR: pistes pour scénariser, évaluer et valoriser l'aprentissage collaboratif. Le français dans le monde, Paris, n. 45, p. 25-34, Janvier 2009.

TAGLIANTE, Christine. L'évaluation et le Cadre Européen Commun. Paris: CLÉ International, 2005.

Recebido em: 24/07/2020

Aceito em: 12/11/2020

Title: Action-based approach assessment and skills integration in foreign language 